\title{
AN INTEGRATIVE MODEL FOR MEASURING GLOB AL PERFORMANCE IN PUBLIC HEALTH SERVICE
}

\author{
Graziella Aghilone* \\ University of Rome "La Sapienza" \\ Facolty of Medicine \\ Roma, RM, ITALY \\ E-mail: graziella.aghilone@uniroma1.it \\ Fabio De Felice \\ University of Cassino \\ Faculty of Engineering \\ Cassino, FR, ITALY \\ E-mail: defelice@unicas.it \\ Antonella Petrillo \\ University of Cassino \\ Faculty of Engineering \\ Cassino, FR, ITALY \\ E-mail: a.petrillo@unicas.it
}

\begin{abstract}
Financial management of modern healthcare organization controls all the assets and liabilities, and makes contributions to the strategic planning process, performance information and cost control. Its function is to achieve performance improvement, guarding assets and resources against waste or loss, to manage human resources and all other kinds of resources. The organization is supported by a governing board that must perform well in order to achieve excellence and accomplish all governance needs. Financial management is a forward-looking activity with long term time horizon so the aim is to balance costs and benefits, improving quality care programs. The health system has to develop strategies for costeffectiveness and rationalization of all the resources involved according to the organizational needs. It is important to create and support an efficient and effective structure. This paper presents a multi-criteria decision analys is by the application of the ANP - Analytic Network Process and the BSC - Balanced Scorecard. The research suggests a new methodological approach that can improve the efficiency of a well managed health organization characterized by multidisciplinary teams that have to interact together in order to gain continuous performance improvement and implement all functions efficiently and effectively.
\end{abstract}

Keywords: ANP, Medical Decision Making, Balanced Scorecard.

\section{Introduction}

A well - managed healthcare organization able to ensure the creation of value-oriented wealth, can acquire strategic competence. For that reason it is important to improve health plans without increasing total costs of care, introduce appropriate programs based on adequate management tools. Management style is very important.

Human resources personnel have huge potentials for creating value, because they provide appropriate care to achieve a good economic and financial balance as the ability how to make good use of available resources. There is a clear need to improve the performance efficiency by a good skilful adaptation too,

\footnotetext{
* Corresponding author
} 
to be applied in all different settings. Whit this analys is, the authors note that the traditional Italian hospital organization is characterised by the separation between clinical and non-clinical professions. There is a certified job classification including a wide variety of positions. For that reason, the authors present three important aspects: 1) the depersonalization of the operator, not related to outcome measures of patient care quality but only to individual interventions; 2) the professional flattening vagueness regarding new technical and operational applications in the healthcare organization; 3) few post-basic courses linking training to the clinical career to distinguish professional competence and relative responsibility.

In this context, the chief of human resource management acts as the principal strategic and operational executive for the whole organization where medicine, nursing, and other clinical professionals collaborate toward a goal of cost - effective care.

The organization's role is to ensure the quality of service, effectiveness, coordination care and the best opportunities for competitiveness on the effective management (Huang et al. 2011).

This paper underlines the human aspect as the strategic link of the whole hospital system; for that reason it proposes the application of the multi-criteria evaluation theory based on the ANP analysis (Saaty,1980) integrated with the balanced scorecard method. In fact, the hospital context involves multidisciplinary profiles that have to cooperate to ensure either an effective and efficient care service or the optimization of all the resources. Optimization of care is to provide the exact combination and timing of all clinical support services required, improving quality and reducing costs. The appropriateness function relates to the marketing function, advising the most economical way to gain all the benefits available; the offered services must be consistent with the strategic plan. For these reasons, as health care public organization is more complex than the private one, the model developed in this paper presents the combination of these two different methodologies because of their specificity dealing with qualitative and quantitative aspects. The objectives to be achieved are different and sometimes contrast each with other.

The Balanced Scorecard is a strategic approach for the variety of processes of the healthcare organization because it reaches important targets and allow to classify alternatives based on a range of criteria.

In this context, the economic - financial indicator, that is an important measurement criterion and performance evaluation, is not adequate to quantify the objectives (Banker, et al. 2004).

By applying of the Balanced Scorecard method, strategies are transformed into a balanced set of indicators (financial and otherwise) related. Therefore, the analys is proceeds from the objective measurement of all the available resources compared with the whole situation, classifying the set of all the most important elements, rather than the fewer ones (Chan, et al. 2006; Ravi et al. 2005). This defines criteria and methodologies designed to identify both qualitative and quantitative improvement of working conditions. The combination of the multicriteria approach $w$ ith the balanced scorecard allows to consider significant roles as "competence", fundamental for human resources organizations (Martinsons, et al. 1999). This combination allows to implement the "control system" too; it is very important to define, to implement and to manage the organization strategic direction, moving it into a complete set of outcome measure performances achieved. In this way, it is proposed to complete the project management of a wellrun organization. If the best solution is the daily challenge of every Chief of Human Resource Management, the multicriteria approach does not present the best situation, but a set of possible solutions. The analysis concerns the identification of defined alternatives from a potentially infinite set of alternatives characterized by a set of constraints (Saaty, 2001). It is important to define the most appropriate method of asset that would provide a representative indicator of the situation. This is possible because of the different weights to each element of the objective on the basis of a higher-level system of values (Saaty, 2005). It is clear that the best solution is the paradigm of the most satisfactory performance with the least expenditure of resources both human and economic. Decision-making model includes the following stages: determination of the priorities according to a predetermined level, the identific ation of the best solution, analys is of a set of possible different solutions 


\section{Healthcare: The strategic role of Human Resource Management}

Human Resource Management is one of the major logistic supports of a healthcare organization; it contributes to fulfill the organization's mission. A strategic human resources management identifies the number and the skill required, recruits them and increases the value of the assets to the organization and the marketplace (Intravaia, 2007). This process involves the organization's resource development strategy and the performance evaluation. The nursing department has become a Knowledge resource and a mechanism for ensuring care across operating systems, planning demand for skill categories, know ledge of market data such as salary and personnel costs.

Both human resources planning activities and relative workforce planning are shown in the following figures 1 and 2.

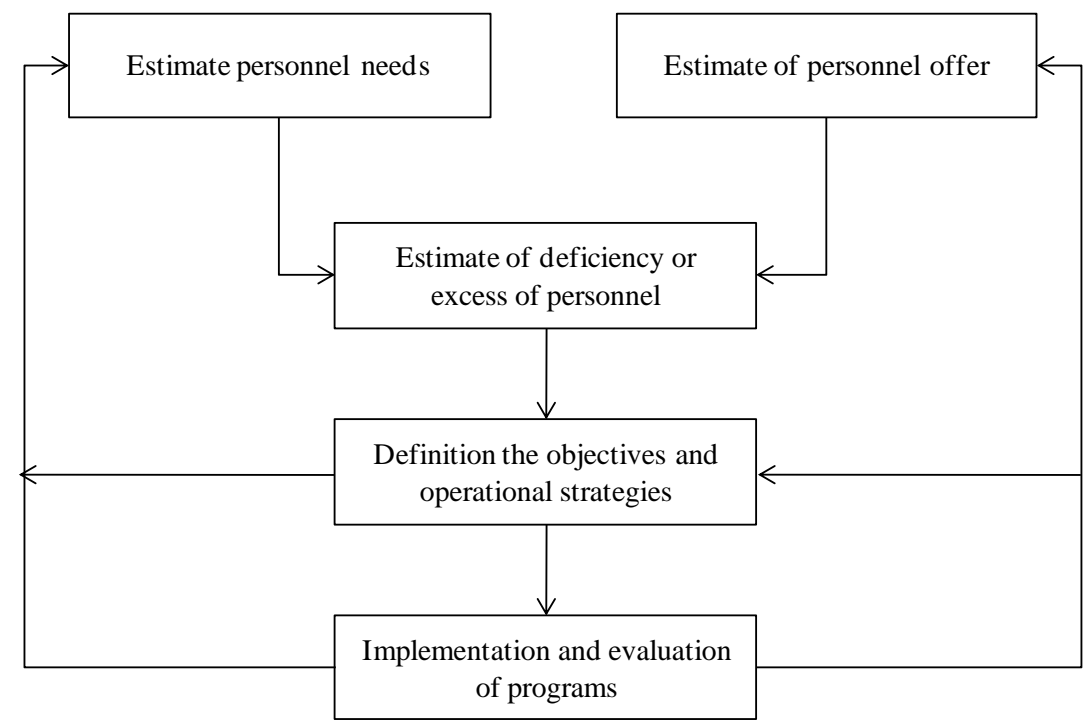

Figure 1: Functions of Human Resources

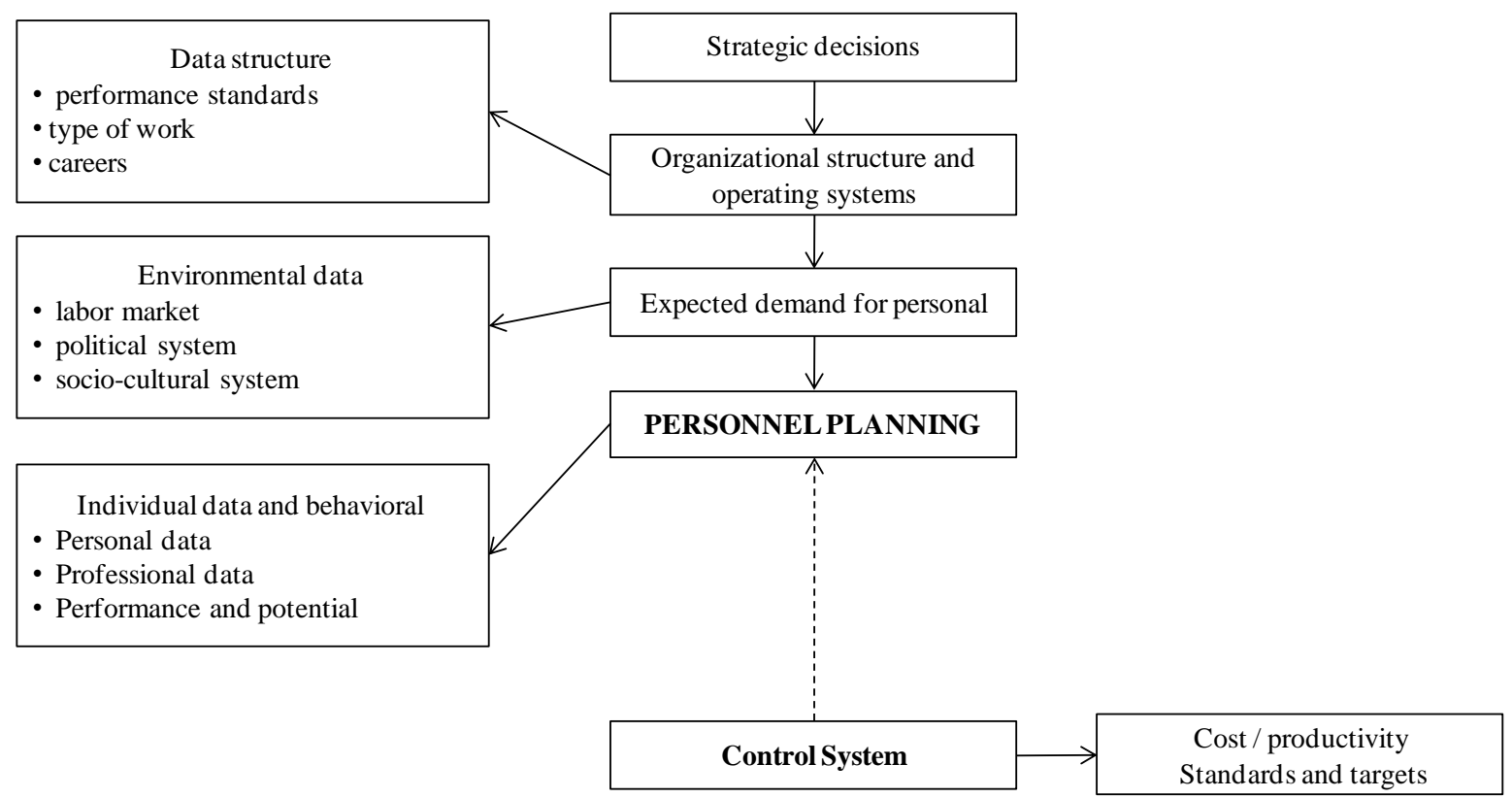

Figure 2: Personnel planning framework 
As well-managed organizations measure the main characteristics of the workforce, workforce planning allows to ensure an adequate human resources organization by developing the following aspects:1) Identifying recruitement needs; 2) Defining the need for staff expertise and qualifications; 3) Requiring particular skills for shortcomings and to fill new activities and new positions; 4) Recruiting and selecting the new staff; 5) Allocating human resources according to priority needs; 6) Putting teams in each area. Data drive human resource planning and identifying important opportunities for improvement (Sprogar, et al. 2002).

The strategy for workforce loyalty manages the full work environment to support associate needs and retention of effective associates. Human resources departments contribute to that strategy through selection, training, measurement of performance and satisfaction (Scuffham, et al. 2001).

As shown in Table 1, the nursing department should include the following functions.

Table 1: Nursing service functions

\begin{tabular}{|c|c|}
\hline Human Resources Management & $\begin{array}{l}\text { - Definition of qualitative - quantitative demand of nurses and } \\
\text { auxiliary personnel. } \\
\text { - Constant analysis of the internal organization of the operational } \\
\text { units. } \\
\text { - Assignment of personnel in the operating units also due to internal } \\
\text { mobility in the Company. } \\
\text { - Preparation and implementation of programs for inclusion in the } \\
\text { organizational context. } \\
\text { Development and application of tools for the enhancement of } \\
\text { professionalism. } \\
\text { Check the presence and distribution of resources also because of } \\
\text { the workloads known or under investigation. }\end{array}$ \\
\hline $\begin{array}{l}\text { Research and continuous } \\
\text { improvement of quality of } \\
\text { nursing care }\end{array}$ & $\begin{array}{l}\text { - Dissemination of knowledge in the context of Clinical Nursing } \\
\text { also through targeted training. } \\
\text { - Coordination of permanent working groups for implementation } \\
\text { and dissemination of programs to improve the quality of nursing } \\
\text { care (nursing folder, procedures, guidelines etc.). }\end{array}$ \\
\hline $\begin{array}{l}\text { Planning and e valuation of } \\
\text { nursing care }\end{array}$ & $\begin{array}{l}\text { - Implementation and deployment of systems and individual } \\
\text { evaluation of nursing care provided. } \\
\text { Promoting the use of rating scales in health care processes in order } \\
\text { to assess the results achieved with objective criteria, the limits for } \\
\text { the achievement of quality standards, and in some cases the } \\
\text { burden of care. }\end{array}$ \\
\hline $\begin{array}{llr}\text { Updating, } & \text { training } & \text { and } \\
\text { professional } & \text { de velopment } & \text { of } \\
\text { nursing } & & \\
\end{array}$ & $\begin{array}{l}\text { - Assessment of training needs, planning, organization and } \\
\text { implementation of training and updating. } \\
\text { - } \quad \text { Mentoring for nurses new acquisition. }\end{array}$ \\
\hline $\begin{array}{l}\text { Procurement of useful resources } \\
\text { to support completion of the } \\
\text { nursing profession }\end{array}$ & $\begin{array}{l}\text { - Assessment of needs through surveys. } \\
\text { - Evaluation and continuous monitoring by means of computerized } \\
\text { material requirements of the barracks and programming } \\
\text { acquisitions and distribution }\end{array}$ \\
\hline
\end{tabular}

\section{Strategy for optimizing resources in nursing: Model ANP-BSC}

A detailed analysis of qualitative parameters proceeds by splitting the investigation object into parts smaller and smaller parts, so it is easier to measure them. The aim is to propose a multicriteria decisional model that supports all the different aspects of the health care system and suggests a global optimization analysis. 
The most important phase is the identification of specific weights for the different elements in order to create a classification. It aims at quantifying relative priorities for a given set of alternatives on a ratio scale, based on judgements of the decision-maker. The attention is focused on monitoring all qualitative elements typical of a health organization. The objective is to introduce a model for the identification of all the healthcare management aspects.

The different steps are:

- STEP 1: Definition of the target; acquiring data, determination of the problem and its goal;

- STEP 2: Identification of critical variables for the evaluation, in order to structure the hierarchy from the top through the intermediate and the lowest levels;

- STEP 3: Construction of the multi-attribute model ANP-BSC;

- STEP 4: Development of performance indicators to be monitored;

- STEP 5: Implementation.

The model ANP - BSC is shown in the following figure 3.

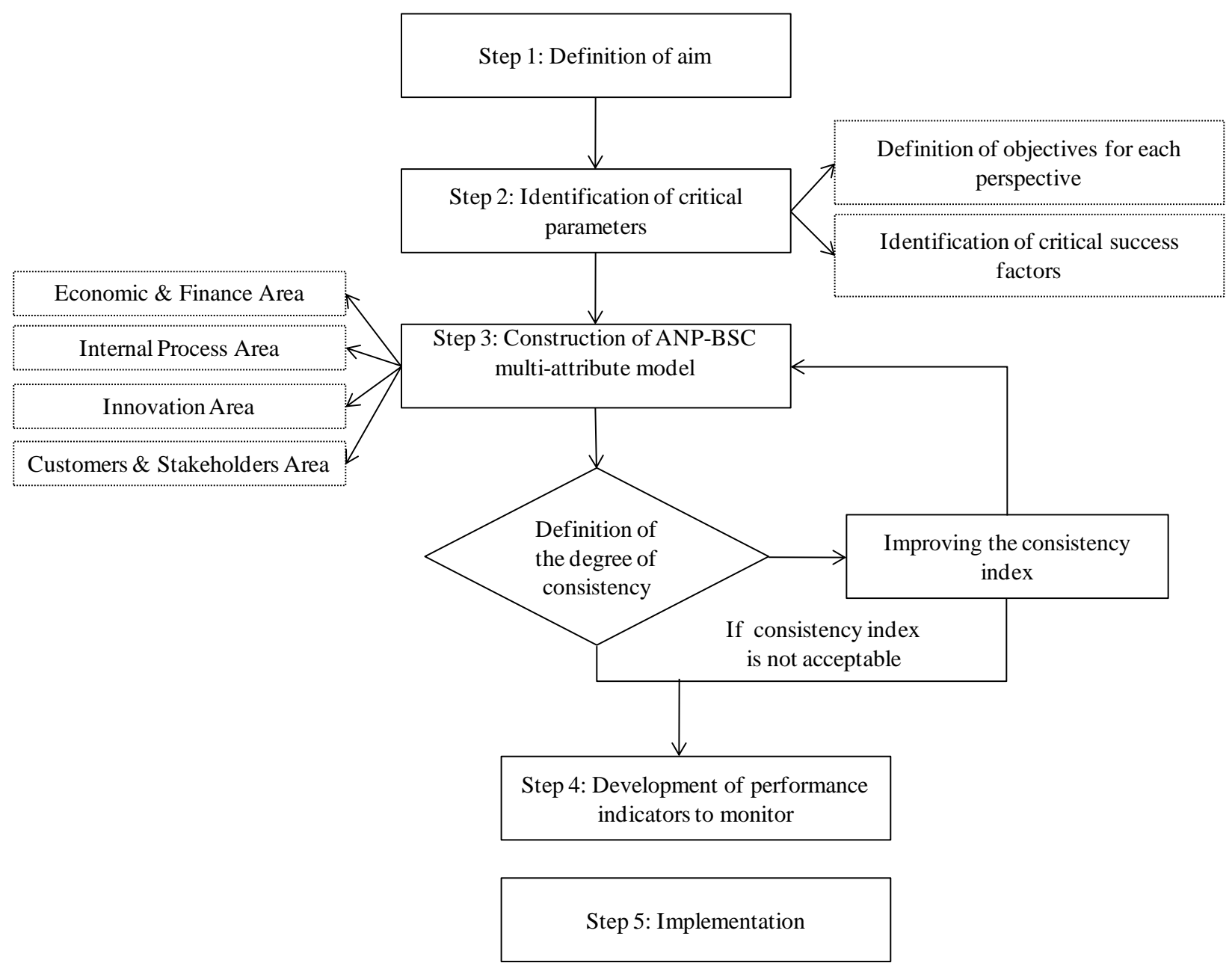

Figura 3: Schema metodologico del modello ANP - BSC.

The methodological steps are:

STEP 1: Definition of the target; acquiring data, determination of the problem and its goal 
The aim of this model is to optimize the management of healthcare organization resources, moving from human resources. The workforce plan is a subsection of the organization's strategic plan; it develops forecasts of the number of persons required in each skill per year for three or five years in the future.

For that reason it is very important to define the parameter time per nurse $(\mathrm{N})$ to be assigned to care technician operator (CTO) or to social health operator (SHO) that is to say to support staff.

Table 3 presents the data of a traditional surgery department in a large hospital in the city.

These data involve different aspects as: 1) the initial numbers of hours performed by nurses and CTO for the different activities during the pre-experimental assessment (indicator of overall demand for service); 2) the weight of each job per hour worked, compared with the total time spent in 24 hours, and expressed as a percentage; 3) workforce planning according to the model chosen; 4) new weight taken as a result of the job; 5) detail of the deviation activities according to the planning model present.

The deviation data demonstrate that some nurses' activities can be ruled by other health figures.

Table 3 shows the classification of the different activities of a surgical ward, the weight given to each job according to human resources. Priority activities, as resources optimization, can improve the integration of different professionals involving: 1) the definition of each job; 2) the number of personnel required distinguishing by nurses, medical and social workforce; 3 ) the determination of competencies;

4) the relationship between health demand as output identification and organizational impact, referring to the hours performed by each resource.

Table 3: Relationship between time/nurse and time/support resources in a great hospital (surgery)

\begin{tabular}{|c|c|c|c|c|c|c|}
\hline Surgery & \multicolumn{3}{|c|}{$\begin{array}{l}\text { Initial situation: number of } \\
\text { hours of work for operator and } \\
\text { activity }\end{array}$} & \multicolumn{3}{|c|}{$\begin{array}{l}\text { Final situation: number } \\
\text { of hours of work for } \\
\text { operator and activity }\end{array}$} \\
\hline ACTIVITY & $\mathrm{N}$ & SHO & Total & $\mathrm{N}$ & $\mathrm{SHO}$ & Total \\
\hline Only Accomodation & 1,00 & 2,00 & 3,00 & 0 & 3 & 3 \\
\hline Basic care & 30,75 & 10,25 & 41,00 & 7,38 & 29,52 & 36,90 \\
\hline Enhanced Service & 25,00 & 1,00 & 26,00 & 25,74 & 2,86 & 36,90 \\
\hline Programming of assistance & 0,00 & 0,00 & 0,00 & 5,72 & 0,00 & 5,72 \\
\hline Management support (verification) & 14,00 & 3,50 & 17,50 & 13,28 & 0,00 & 13,28 \\
\hline $\begin{array}{lll}\begin{array}{l}\text { Management } \\
\text { reorganization) }\end{array} & \text { support } & \text { (with }\end{array}$ & 7,75 & 2,00 & 9,75 & 0,00 & 9,75 & 9,75 \\
\hline Total & 78,50 & 18,75 & 97,25 & 52,12 & 45,13 & 97,25 \\
\hline Weight of the operators & 80,72 & 19,28 & 100,00 & 53,59 & 46,41 & 100,00 \\
\hline
\end{tabular}

\section{STEP 2: Identification of critical variables for evaluation.}

The data presented in table 3 shows how the TO/SO lead nurses to focus on care and planning.

The operating room and hospitalization are the scenarios of this analysis. As the safety of each patient depends on both team's performance and well- managed hospital, all health professionals collaborate with each other, fulfilling the strategic mission. The patient conditions determine job priorities in the department; the organization requires a teamwork by delegation or by supervision, according to an equitable distribution of workload.

This analysis explains how social health professionals can improve the whole ward activities. In fact, they may implement nurse care, promote the use of less skilled professionals, reducing the cost of care, maintaining service and quality. In Italy, the social health profile was introduced on 22.2.2001, by the Permanent Conference for Relations between State, Regions and the Autonomous Provinces of Trento and Bolzano. It defines the operator's duty. The operator has to satisfy the initial expectations of the patient's care, differing from other professionals for skills, responsibility and autonomy. Support staff operators provide an important opportunity for cost reduction; if they are appropriately supervised, they 
may provide care. A support staff in a department generates the decrease of hours per nurse performing basic tasks; the hours for direct patient care activities increase for the benefit of the quality of service provided.

Identify all critical variables, the authors propose a model in which the starting point is a critical variable

STEP 3: Construction of the multi-attribute model ANP-BSC

The starting points of the example proposed model move from the following objectives:

- to ensure adequate human resources to the workload;

- to reach standards for accuracy and safety;

- to achieve an appropriate pattern of cost/quality/satisfaction trade-offs.

The model depends on the consideration that the strategic Balanced Scorecard method quantifies the performance according to four concepts that determine competitive success:

- financial performance as ability to acquire and reinvest essential resources;

- market performance and customer satisfaction;

- internal operations as ability to provide a competitive service;

- ability to adapt and improve as availability of emerging methods of care or ability to implement changes in customer attitudes and economic environment.

By combining the four dimensions or criteria with three different alternatives, the authors present a global analysis. The application of the balanced scorecard method requires the financial performance to balance the budget, while the more critical aspect concerns patient satisfaction. The summary specific measures, established to define this model, are shown in table 4.

Table4: Critical parameters identified

\begin{tabular}{|l|l|l|}
\hline Criteria & Sub Criteria & $\begin{array}{l}\text { Levels of performance in } \\
2009 \text { compared to 2008 }\end{array}$ \\
\hline \multirow{2}{*}{$\begin{array}{l}\text { Economic \& Finance } \\
\text { Area }\end{array}$} & Revenues & $\begin{array}{l}-1.051 .534 € \\
2.321 .687 € \\
\end{array}$ \\
& $\begin{array}{l}\text { Production value } \\
\text { Difference between cost and value of } \\
\text { production }\end{array}$ & $\begin{array}{l}1.801 .704 € \\
-4.715 .691 €\end{array}$ \\
\hline Internal Process Area & Provision of hos pital stay & $-127.840 €$ \\
& Purchase consumer goods & $4.440 .70 €$ \\
\hline Innovation Area & Maintenance & $-83.681 €$ \\
& Training & $-165.748 €$ \\
\hline Customers & Technical Services & $589.551 €$ \\
Stakeholders Area & Purchase of health services & $-1.657 .785 €$ \\
\hline
\end{tabular}

Specifications for the three alternatives are show in Table 5.

Table 5: Alternatives description

\begin{tabular}{|l|l|}
\hline Alternatives & Descriptions \\
\hline $\begin{array}{l}\text { A1. Organization and } \\
\text { administration (staff and } \\
\text { management) }\end{array}$ & $\begin{array}{l}\text { Implement an organizational model able to manage the } \\
\text { contributions (behaviors and results) of all employees and able to } \\
\text { link the activities of employees with corporate objectives. }\end{array}$ \\
\hline $\begin{array}{l}\text { A2. Quality of process (adjustment } \\
\text { to the operational guidelines and } \\
\text { appropriateness) }\end{array}$ & $\begin{array}{l}\text { Investing in innovative health services and adjust the ir structures } \\
\text { in accordance with the guidelines and regulations }\end{array}$ \\
\hline A3. Upgrading of facilities (space & Investing in the strengthening of health in terms of space and \\
\hline
\end{tabular}




\begin{tabular}{l|l}
\hline and equipment) & equipment.
\end{tabular}

After establishing the basic requirements we have built the ANP-BSC model and we have assigned weights, results of specific assessment by a team of experts from of satisfaction expectations.

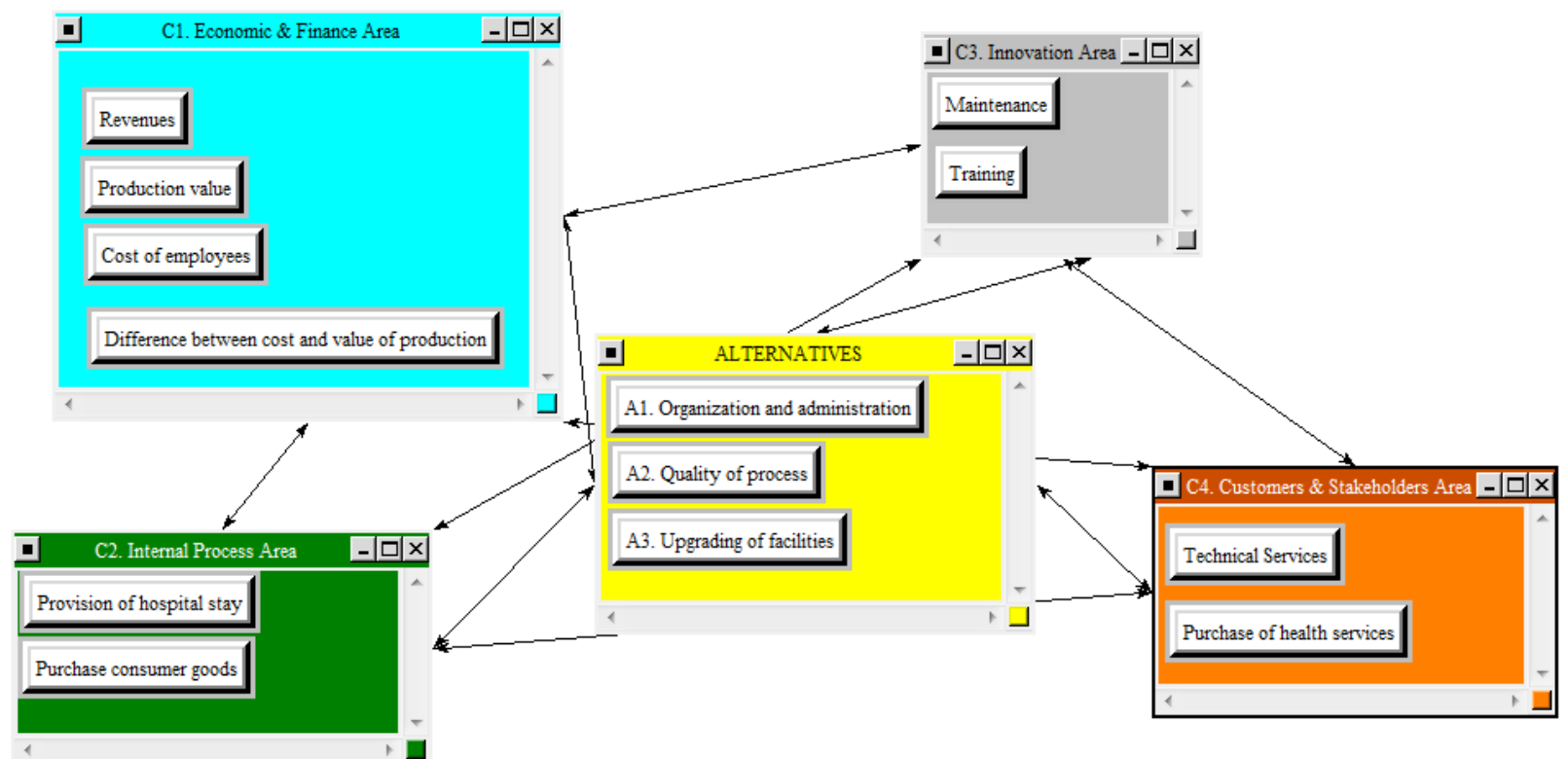

Figure 4: ANP - BSC Model

The results show that it is possible to use a mixture of different measures to achieve improvements in a balanced context of critical success elements. "It's a strategical integration".

The priority set of activities obtained with the evaluation of the measurement indicators of the ANP-BSC is represented in Table 6.

Table: Priority

\begin{tabular}{|l|l|}
\hline Criteria and Subcriteria & Score \\
\hline A1. Organization and administration & 0.482 \\
\hline A2. Quality of process & 1.00 \\
\hline A3. Upgrading of facilities & 0.688 \\
\hline Revenues & 0.199 \\
\hline Production value & 0.400 \\
\hline Cost of employees & 0.183 \\
\hline $\begin{array}{l}\text { Difference between cost and value of } \\
\text { production }\end{array}$ & 0.216 \\
\hline Prestazioni di degenza ospedaliera & 0.591 \\
\hline Purchase consumer goods & 0.408 \\
\hline Maintenance & 0.389 \\
\hline Training & 0.610 \\
\hline Technical Services & 0.377 \\
\hline Purchase of health services & 0.622 \\
\hline
\end{tabular}


STEP 4: Development of performance indicators to monitor the previous analysis

These criteria have not the same value to contribute to effectiveness and efficiency of the health service. Therefore it is important to establish an evaluation system that would allow to highlight and measure all the performances of the healthcare organization (De Felice A. Petrillo, 2009).

So, the authors have chosen to introduce evaluation criteria based on the scores tied to annual performance improvement that each healthcare organization has to record.

In other words, as the performance measurement concerns the organization, the authors have decided to complete the model by introducing some indicators. Quality is measured by clinical outcomes, process and structural approaches. The most important aspects chosen to define a quality evaluation are:

- DM Average length of stay (days of care consumed/patients treated and cost/case);

- $\mathrm{C} / \mathrm{R}$ The effect of structural costs on revenues;

- N/S Number of new services;

- T/S Time per services of first aid;

- L/E Training hours per employee.

The analysis is described in the following tables (Table 7 and 8)

Table 7: Evaluation criteria

\begin{tabular}{|l|l|l|}
\hline Parame ter & \% Yearly Increase & Score \\
\hline DM Index & $15-20$ & 10 \\
\cline { 2 - 3 } & $30-50$ & 30 \\
\cline { 2 - 3 } & $>50$ & 50 \\
\hline CR Index & $>20 \%$ & 10 \\
\cline { 2 - 3 } & $15 \%-20 \%$ & 30 \\
\cline { 2 - 3 } & $<15 \%$ & 50 \\
\hline NS Index & $5-10$ & 10 \\
\cline { 2 - 3 } & $10-15$ & 30 \\
\cline { 2 - 3 } & $>20$ & 10 \\
\hline \multirow{5}{*}{ TS Index } & $30 \mathrm{~min}$ & 30 \\
\cline { 2 - 3 } & $1 \mathrm{~h}$ & 50 \\
\cline { 2 - 3 } & $>1 \mathrm{~h}$ & 10 \\
\hline \multirow{5}{*}{ FL Index } & $8 \mathrm{~h}$ & 30 \\
\cline { 2 - 3 } & $12 \mathrm{~h}$ & 50 \\
\cline { 2 - 3 } & $>20 \mathrm{~h}$ & \\
\hline
\end{tabular}

STEP 5: Implementation

The implementation model defines the specific target and (Table 8) identifies improvement targets for each area analyzed.

Table 8: Global Rating

\begin{tabular}{|l|l|l|}
\hline Judgment & Range & Globale Assessment \\
\hline Low & $0-30$ & $\begin{array}{l}\text { "Managing unfit" } \\
\text { Little ability to promote effective and efficient actions. }\end{array}$ \\
\hline Mediu & $30-90$ & $\begin{array}{l}\text { "Proper management" } \\
\text { Good management skills. }\end{array}$ \\
\hline
\end{tabular}




\begin{tabular}{|l|l|l|}
\hline High & $90-150$ & $\begin{array}{l}\text { "Excell management". } \\
\text { Synergistic view of the various aspects of the business } \\
\text { Ability to choose between the best alternatives. }\end{array}$ \\
\hline
\end{tabular}

\section{Conclusions}

The present method allows to identify a set of best practices for a well-managed healthcare organization. This model establishes the health improvement goals because it translates the strategic mission, vision and plan into real objectives and measures. In well-managed organizations, these transactions arise from strategic opportunities previously considered. In particular, the four perspectives proposed are:

establish the possible equilibrium between short, medium and long range planning objectives; indicators designed to control value created for external stakeholders - that is for shareholders and customers - and specific measures to control critical business processes, innovation, learning and growth; lagging indicators and leading indicators; objective - quantifiable and subjective measures that are more flexible and useful as future performances driver.

According to this logic, it is possible to generate a new management system based on the combination of short- range and strategic long-range objectives ones creating a "coherent system of measurement and control system". This model, based on a balanced scorecard approach, needs some months, although the involvement required is longer.

\section{REFERENCES}

R. D. Banker, H. Chang, M. J. Pizzini, (2004). The balanced scorecard: Judgmental effects of performance measures linked to strategy. Accounting Review, 79(1), 1-23.

Y. C. L, Chan, (2006). An analytic hierarchy framework for evaluating balanced scorecards of healthcare organizations. Canadian Journal of Administrative Sciences, 23(2), 85-101.

F. De Felice A. Petrillo, Proposal of a new model for the optimization of the organizational process in industrial company through the application of the Analytic Network Process. Proceedings of the International Conference on Modelling \& Applied Simulation, Porto de la Cruz (Tenerife), 23-25 September, 2009.

G. Intravaia. Management of human resources in different settings of palliative care. Health Centre "La Maddalena”, Palermo 2007.

H. Huang, M. Lai, L. Lin. Developing strategic measurement and improvement for the biopharmaceutical firm: Using the BSC hierarchy. Expert Systems with Applications 38 (2011) 4875-4881.

M. Martinsons, R. Davison, D. Tse. The balanced scorecard: a foundation for the strategic management of information systems. Decision Support Systems 25 (1999) 71-88.

M. Sprogar, M. Leni, Silvia Alayon. Evolution in Medical Decision Making. Journal of Medical Systems, Vol. 26, No. 5, 2002.

Regione Emilia Romagna, Bologna Health Centre - Policlinico S. Orsola - Malpighi. Direction of the nursing service. Regulations for management of nursing service personnel. Bologna 1998.

Regional Health Service, - University of Modena. Report 2009 
Saaty, T.L., (1980). The Analytic Hierarchy Process. McGraw-Hill, New York NY.

Saaty, T.L., (2001). Decision making with independence and feedback: The Analytic Network Process, Pittsburgh, RWS Publications.

Saaty, T.L. (2005). Theory and Applications of the Analytic network Process: decision making with benefits, opportunities, costs, and risks. Pittsburg, PA: RWS Publications.

V. Ravi, Ravi Shankara, M.K. Tiwari. Analyzing alternatives in reverse logistics for end-of-life computers: ANP and balanced scorecard approach. Computers \& Industrial Engineering 48 (2005) 327356.

P. Scuffham, J. Posnett, P. West. Health economics in decision making for influenza management. International Congress Series 1219 (2001) 81-85. 